\title{
Revisão taxonômica de Kanaima Distant (Hemiptera, Cercopidae, Ischnorhininae)
}

\author{
Andressa Paladini ${ }^{1,2} \&$ Gervásio Silva Carvalho ${ }^{1,3}$
}

\begin{abstract}
${ }^{1}$ Laboratório de Entomologia. Departamento de Biodiversidade e Ecologia. Pontifícia Universidade Católica do Rio Grande do Sul, Faculdade de Biociências, Av. Ipiranga, 6681, Partenon, 90619-900, Porto Alegre-RS, Brasil.

${ }^{2}$ Bolsista do CNPq (Mestrado) do Programa de Pós-Graduação em Zoologia. andri_bio@yahoo.com.br ${ }^{3}$ Pesquisador do CNPq.
\end{abstract}

\begin{abstract}
Taxonomic revision of Kanaima Distant (Hemiptera, Cercopidae, Ischnorhininae). Kanaima Distant, 1909 is revised; the species are described and redefined. This work presents characteristics of the species of Kanaima, important characters of the external morphology and the genitalia. Four species are recognized as valid: K. katzensteinii (Berg, 1879), K. fluvialis (Lallemand, 1924), K. fusca (Lallemand, 1927) n. comb., and K. nigra n. sp. (Brasil, RS). The names Monecphora fluvialis var. lateralis Lallemand, 1924 and Monecphora fluvialis var. bipunctata Lallemand, 1924 are synonymized under Kanaima fluvialis. Four species enclosed in Kanaima are transferred to Mahanarva: M. (Ipiranga) vittata (Walker, 1851) n. comb., M. (Ipiranga) fortunata (Lallemand, 1924) n. comb., M. (Mahanarva) radiata (Walker, 1851) n. comb. and M. (Mahanarva) dubia (Stancik \& Cavichioli, 2003) n. comb. Pachypterinella Lallemand, 1927 n. syn.
\end{abstract}

KEYWORDS. Eryngium; Neotropical; Systematic; Tomaspidini.

\begin{abstract}
RESUMO. Revisão taxonômica de Kanaima Distant (Hemiptera, Cercopidae, Ischnorhininae). Kanaima Distant, 1909 é revisado, sendo suas espécies descritas e redefinidas. Este trabalho ressalta os caracteres taxonomicamente importantes das espécies de Kanaima, como os da morfologia externa e da genitália. Quatro espécies são reconhecidas como válidas: K. katzensteinii (Berg, 1879), K. fluvialis (Lallemand, 1924), K. fusca (Lallemand, 1927) comb. nov., e K. nigra sp. nov. (Brasil, RS). Os nomes Monecphora fluvialis var. lateralis Lallemand, 1924 e Monecphora fluvialis var. bipunctata Lallemand, 1924 são sinonimizados sob Kanaima fluvialis. Quatro espécies incluídas em Kanaima são transferidas para Mahanarva: M. (Ipiranga) vittata (Walker, 1851) comb. nov., M. (Ipiranga) fortunata (Lallemand, 1924) comb. nov., M. (Mahanarva) radiata (Walker, 1851) comb. nov. e M. (Mahanarva) dubia (Stancik \& Cavichioli, 2003) comb. nov. Pachypterinella Lallemand, 1927 sin. nov.
\end{abstract}

PALAVRAS-CHAVE. Eryngium; Neotropical; sistemática; Tomaspidini.

Kanaima Distant,1909 (Tomaspidini) é caracterizado por incluir espécies de porte médio, com vértice grande, largo e levemente carenado no centro; tégminas com venação reticulada e proeminente na região apical; pernas moderadamente robustas, tíbias posteriores com 16 espinhos apicais, artículo basal dos tarsos com mais de 15 espinhos apicais distribuídos em três fileiras e muitas vezes ocultos por longas cerdas. O posclípeo inflado e sua forte inclinação para trás, constituem os principais caracteres das espécies do gênero. Em geral a coloração é escura, tendendo do castanho para o preto. Atualmente as espécies distribuem-se no Brasil e Argentina.

São poucos os trabalhos que tratam da biologia das espécies e de suas plantas hospedeiras, os únicos dados referentes a estes aspectos estão nos trabalhos de Cavichioli $(1987,1988)$ e Stancik \& Cavichioli (2003) os quais constataram que três espécies de Kanaima ocorrem sobre Eryngium (Apiaceae): K. fluvialis, K. katzensteinii e K. dubia. Fennah (1979) cita que espécimes de Kanaima vittata foram coletados em Digitaria decumbens, Hyparrhenia rufens e Paspalum sp., todas incluídas em Poaceae.

Walker (1851) descreveu Monecphora radiata e
Monecphora vittata utilizando poucas informações morfológicas e mencionando as suas localidades-tipo, Venezuela e América do Sul, respectivamente. Lallemand (1912) transferiu essas espécies para Tomaspis Amyot \& Serville, 1843 e, em 1924, descreveu Monecphora fortunata. Fennah (1968) revisando os gêneros de cercopídeos do Novo Mundo incluiu M. fortunata em Maxantonia Distant, 1909. O mesmo autor em 1979, complementando a sua revisão de 1968 sinonimizou $T$. vittata com $M$. fortunata incluindo-a em Kanaima. Carvalho \& Webb (2005) revalidaram o status de $K$. fortunata.

Berg (1879) descreveu Tomaspis katzensteinii ressaltando principalmente caracteres morfológicos e alguns aspectos referentes à coloração, incluiu medidas dos exemplares e a distribuição geográfica. Distant (1909) descreveu Kanaima com base em Tomaspis katzensteinii. Lallemand (1912) e Delétang (1917) redescreveram o gênero em questão; sendo que Lallemand (1912) comentou que Kanaima é muito próximo de Mahanarva.

Lallemand (1924) descreveu Monecphora fluvialis. Observou a grande variação no padrão alar e, em consequiência disso, reconheceu duas variedades: $M . f$. var. lateralis com 
somente duas máculas laterais externas no cório; $M . f$. var. bipunctata, com os terços basal e mediano, e duas máculas no terço apical, vermelhas.

Fennah (1968) redescreveu Kanaima com base nas estruturas da cabeça, dos tarsos das pernas posteriores, incluindo características da genitália do macho. Além disso, o autor incluiu Monecphora fluvialis em Kanaima. Cavichioli (1987) em trabalho de biologia de Kanaima fluvialis acrescentou informações ecológicas e fez descrições detalhadas de todos os ínstares, incluindo a forma adulta. O mesmo autor realizou em 1988 um estudo sobre a morfologia da espécie.

Stancik \& Cavichioli (2003) descreveram uma nova espécie, Kanaima dubia, onde citaram a dificuldade de enquadrar a espécie em Kanaima ou Mahanarva, em razão das semelhanças com ambos os gêneros.

\section{MATERIALE MÉTODOS}

Foram examinados 217 espécimes procedentes das seguintes instituições: The Natural History Museum, London (BMNH); Coleção de Entomologia Pe. J. S. Moure, Departamento de Zoologia, Universidade Federal do Paraná, Curitiba (DZUP); Museu de Ciências e Tecnologia, Pontifícia Universidade Católica do Rio Grande do Sul, Porto Alegre (MCTP); Museu de Zoologia, Universidade de São Paulo, São Paulo (MZSP); Zoological Museum, University of Copenhagen, Denmark (ZMUC, anteriormente LUND).

Para a identificação das espécies buscou-se examinar os tipos ou recorreu-se ao material comparado com os mesmos e fotografias dos exemplares tipos.

Os termos adotados foram os comumente utilizados para Cercopidae; as estruturas da cabeça foram nomeadas conforme Hamilton (1981) e Fennah (1968); para a da genitália segundo Fennah (1968) para as fêmeas Nielson (1965); para as demais estruturas Snodgrass (1935).

Os dados do material examinado são apresentados conforme encontrados nas etiquetas e/ou catálogos, segundo Papavero (1994). Os exemplares foram examinados sob estereomicroscópio; as medidas foram tomadas com uma ocular micrométrica; as dimensões correspondem à média em milímetros de no máximo 10 exemplares ( 5 machos e 5 fêmeas). $\mathrm{O}$ abdomem dos machos e das fêmeas foram destacados, colocados em hidróxido de sódio a 10\% (a frio) para clarificação por aproximadamente 17 horas, após foi feita série alcoólica para desidratação lenta do material; as peças secas foram extraídas e fixadas sobre cilindro de alumínio com fita adesiva de carbono. Em seguida passaram por processo de metalização para posterior análise no Microscópio Eletrônico de Varredura (MEV-Philips modelo XL 30) no Centro de Microscopia e Microanálises (CEMM) da PUCRS.

\section{RESULTADOS EDISCUSSÃO}

\section{Kanaima Distant, 1909}

Espécie-tipo: Tomaspis katzensteinii Berg, 1879, por designação original.
Kanaima Distant, 1909: 212; Carvalho \& Webb, 2005: 65.

Pachypterinella Lallemand, 1927: 208; Carvalho \& Webb, 2005: 83. Espécie-tipo: Pachypterinella fusca Lallemand, 1927, por designação original. syn. nov.

Redescrição. Cabeça mais larga que o comprimento do vértice, este mais largo do que longo, com carena mediana distinta; posclípeo inflado, de perfil recuado, com carena longitudinal distinta e proeminente (K. fluvialis) ou ausente (K. katzensteinii), ranhuras laterais grosseiramente marcadas; antenas com pedicelo mais longo do que largo, corpo basal do flagelo subcilíndrico, projetado para fora do pedicelo, portando uma arista menor do que este; anteclípeo maior que o último artículo do rostro, sendo este menor que o anterior; rostro se estendendo até às mesocoxas. Tégminas estreitas com venação proeminente, terço apical pouco ou muito reticulado $(K$.

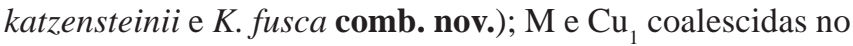
terço basal, $\mathrm{A}_{1}$ e $\mathrm{A}_{2}$ distintas. Asas posteriores com $\mathrm{Cu}_{1}$ não espessada na base. Perna posterior: tíbia com dois espinhos laterais, sendo o basal de mesmo tamanho que aqueles situados na coroa apical, estes em número de 16 distribuídos em duas fileiras, basitarso com 20 a 40 espinhos apicais distribuídos em três fileiras e cobertos por uma densa camada de cerdas; processo subungueal ausente. Pigóforo com um processo lateral digitiforme entre o tubo anal e a placa subgenital, esta longa com ápice arredondado; edeago subcilíndrico com processos dorsais curtos em relação à haste (do ponto de inserção do processo até a extremidade apical) e dirigidos para frente; parâmeros subretangulares com elevação basal pouco desenvolvida, dente apical voltado para dentro, podendo apresentar um intumescimento em sua base. Primeira valva do ovipositor com processo basal pouco desenvolvido.

Comentários. Este gênero foi incluído dentro do complexo Mahanarva por Lallemand (1924) tendo como caráter marcante a conformação do posclípeo. Devido ao compartilhamento de caracteres referentes à genitália: como a forma do edeago $\mathrm{e}$ dos pârameros, e semelhanças na morfologia externa Pachypterinella é sinônimo de Kanaima.

Chave para identificação das espécies:

1. Posclípeo sem carena longitudinal; tégminas castanhoamareladas K. katzensteinii

Posclípeo com carena longitudinal; tégminas de outra coloração 2

2. Margens ântero-laterais do pronoto convexas; tégminas escuras com máculas vermelhas variando em posição e tamanho K. fluvialis

Margens ântero-laterais do pronoto retas; tégminas escuras sem máculas distintas

3. Tégminas castanho-escuras; comprimento total de 13-14 $\mathrm{mm}$; edeago com os processos dorsais situados na metade K. fusca comb. nov.

Tégminas negras; comprimento total de $8-10 \mathrm{~mm}$; edeago com processos dorsais situados antes da metade ...... K. nigra sp. nov. 


\section{Kanaima katzensteinii (Berg, 1879)}

(Figs. 1-16; 64, 70)

Tomaspis katzensteinii Berg, 1879: 214.

Kanaima katzensteini [sic]; Distant, 1909: 213.

Kanaima katzensteinii; Carvalho \& Webb, 2005: 66.

Medidas (em mm) Macho/Fêmea. Comprimento da cabeça: 1,5/1,6; largura da cabeça: 3,4/3,6; diâmetro do ocelo: 0,1/0,1; distância interocelar: 0,4/0,4; distância ocelo-ocular: 0,8/0,8; distância ocelo-margem posterior: $0,3 / 0,3$; distância interocular: 1,4/2,1; comprimento do tilo: 0,7/0,8; largura do tilo: 1,5/1,8; comprimento do posclípeo: 2,3/2,5; largura do posclípeo: 1,7/ 1,9; comprimento do pronoto: $2,8 / 2,9$; largura do pronoto: $4,4 /$ 4,6; comprimento do escutelo: 2,3/2,5; largura do escutelo: $1,8 / 2,1 ;$ comprimento da tégmina: $11,3 / 12$; largura da tégmina: $3,3 / 3,8 ;$ comprimento total: $13,8 / 15,4$.
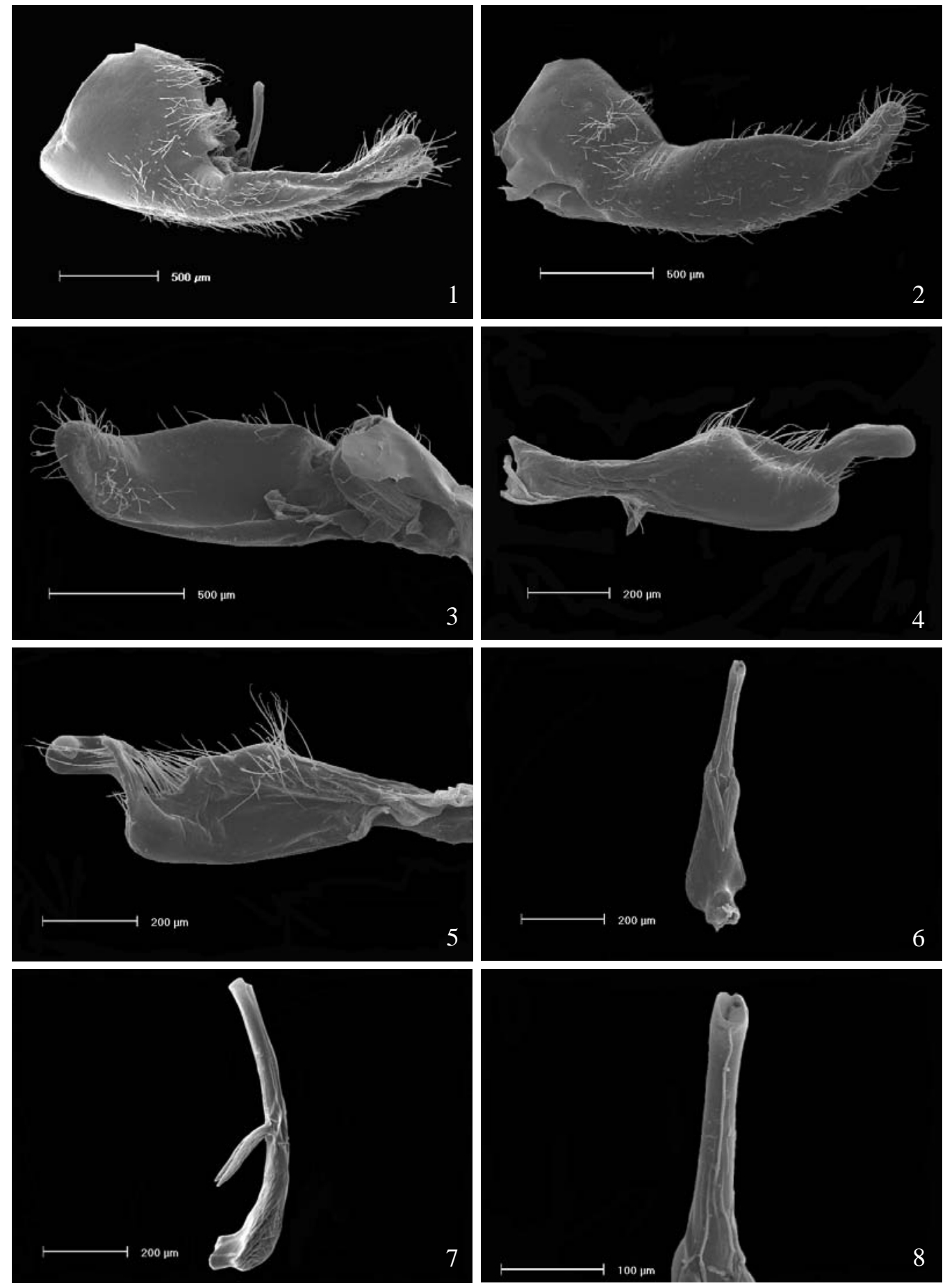

Figs. 1-8. Kanaima katzensteinii, $\sigma^{\star}$. 1, pigóforo, vista lateral; placa subgenital: 2, vista lateral externa; 3, vista lateral interna; parâmero: 4, vista lateral externa; 5, vista lateral interna; edeago: 6, vista dorsal; 7 , vista lateral; 8, ápice. 
Caracteres diagnósticos. Coloração geral escura, tégminas castanho-amareladas. Tórax e abdômen negros com as margens dos segmentos amareladas. Pernas negras (Figs. $64 \mathrm{e}$ 70).

Redescrição. Macho. Cabeça negra, mais larga que o comprimento do vértice, este com duas impressões externas aos ocelos; carena mediana aparente, leve pubescência dourada e finas puncturações; margem suprantenal enegrecida e bastante enrugada; tilo retangular, negro, duas vezes mais largo que longo, com superfície puncturada e carena mediana pouco marcada; ocelos castanhos, separados entre si por mais de um diâmetro de um deles, mais próximos um do outro do que dos olhos e da margem posterior da cabeça; olhos castanho-claros, proeminentes e dispostos transversalmente; antenas com pedicelo castanho-escuro, mais longo que largo, visível dorsalmente, flagelo com corpo basal castanho, subcilíndrico, projetado para fora do pedicelo, com arista menor que este; posclípeo negro, muito inflado, de perfil recuado, mais longo do que largo, sem carena longitudinal, com ranhuras laterais grosseiramente marcadas; anteclípeo negro, maior que o último artículo do rostro e este menor que o anterior; rostro castanho-enegrecido atingindo as mesocoxas. Pronoto hexagonal, mais largo que longo, com a área anterior negra e a posterior castanha, grosseiramente puncturado, com carena mediana pouco marcada; margem anterior reta, ântero-laterais retas, póstero-laterais sinuosas formando uma concavidade, posterior chanfrada com reentrância mediana; ângulos umerais arredondados; escutelo negro com concavidade mediana e rugosidades transversais. Tégminas estreitas, finamente puncturadas, castanho-amareladas, com fina pubescência; $\mathrm{M}$ e $\mathrm{Cu}_{1}$ coalescidas no terço basal; $\mathrm{A}_{1}$ e $\mathrm{A}_{2}$ distintas, reticulação apical desenvolvida, venação proeminente. Asas hialinas com venação castanho-clara, $\mathrm{Cu}_{1}$ não espessada na base. Pernas posteriores: fêmur com espinho conspícuo na face interna; tíbia com dois espinhos laterais, sendo o basal de igual tamanho dos apicais, estes em número de 15 dispostos em duas fileiras; basitarso com 36 a 40 espinhos apicais dispostos em três fileiras, recobertas por uma densa camada de longas cerdas; processo subungueal ausente.

Genitália do macho. Pigóforo com um processo lateral entre o tubo anal e a placa subgenital (Fig. 1), sendo esta longa em relação ao conjunto, com o ápice arredondado (Figs. 2 e 3); parâmeros subretangulares com dente apical voltado para dentro; elevação dorsal pouco desenvolvida; margem dorsal e anterior com um conjunto de cerdas (Figs. 4 e 5); edeago subcilíndrico com ápice truncado, processos dorsais curtos em relação à haste, retos, voltados para baixo e inseridos no centro, com menos da metade do comprimento total do edeago (Figs. 6-8).

Fêmea. Semelhante ao macho, somente um pouco maior. Primeira valva do ovipositor longa e delgada com ápice acuminado, munida de um processo basal arredondado, pouco desenvolvido, em forma de calcanhar, voltado para trás (Figs.
9 e 10); segunda valva do ovipositor longa, com ápice arredondado, margem dorsal com um conjunto de dentes que se limitam ao início do terço apical (Figs. 11 e 12), face externa com um conjunto de sensilas dispostas próximas à margem dorsal e ao ápice, face interna com ornamentações laminares (Figs. 14 e 15); terceira valva curta e larga, com longas cerdas na face ventral e ornamentações na face interna (Figs. 13 e 16).

Comentários. K. katzensteinii é semelhante a K. nigra sp. nov., $K$. fusca e $K$. fluvialis compartilhando com elas os seguintes caracteres: dentículos da face interna da placa subgenital limitando-se à margem dorsal desta; processos medianos curtos em relação à haste do edeago e ápice do edeago alargado em vista lateral. A espécie possui o posclípeo muito inflado com ausência de carena longitudinal. $K$. katzensteinii tem como hospedeiro um caraguatá de banhado (Eryngium sp.).

Material examinado: BRASIL, Paraná: Curitiba, 10.XI.1980, A Lozovei leg., 16 machos, 11 fêmeas (DZUP); idem 7.XI.1965, P.J.S. Moure leg., 1 macho (DZUP); idem, 6.XI.1981, A.M. Sakakibara \& R.R. Cavichioli leg., 1 macho, 1 fêmea (DZUP); São José dos Pinhais, 28.X.1980, A. Lozovei leg., 2 machos (DZUP); Ponta Grossa, XII.1942, (sem coletor), 1 fêmea (DZUP); Rio Grande do Sul: Caxias do Sul, 11.XI.1995, E.E.F.II-PG-ZOO leg., 10 machos, 3 fêmeas (MCTP); Pelotas, XI.1995, C. Costa leg., 1 fêmea (MCTP); idem, 12.XI.1983, Rurtel leg., 1 fêmea (MCTP); Santa Maria, 07.X.1978, Mayer leg., 1 fêmea (MCTP); Guaíba, 28.XI.1987, G.S. Carvalho leg., 1 macho (MCTP); idem, 02.XI.1992, G.S. Carvalho leg., 1 macho (MCTP); Arroio Araçá, Barra do Ribeiro, 09.XI.2003, G.S. Carvalho leg. 1 macho (MCTP); Porto Alegre, 26.XI.1980, G.S. Carvalho, leg., 2 machos (MCTP). Argentina: Buenos Aires, Delta del Paraná, I.1945, (sem coletor), 2 fêmeas (DZUP).

$$
\begin{gathered}
\text { Kanaima fluvialis (Lallemand, 1924) } \\
\text { (Figs. 17-32; 65-67; 71-73) }
\end{gathered}
$$

Monecphora fluvialis Lallemand, 1924: 380

Monecphora fluvialis var. lateralis Lallemand, 1924: 380. syn. nov. Monecphora fluvialis var. bipunctata Lallemand, 1924: 381. syn. nov. Kanaima fluvialis; Fennah, 1968: 181; Carvalho \& Webb, 2005: 65. [Kanaima fluvialis] ssp. bipunctata; Carvalho \& Webb, 2005: 65. [Kanaima fluvialis] ssp. lateralis; Carvalho \& Webb, 2005: 65.

Medidas (em mm). Macho/Fêmea. Comprimento da cabeça: 1,2/1,4; largura da cabeça: 2,6/2,9; diâmetro do ocelo: 0,1/0,1; distância interocelar: 0,3/0,3; distância ocelo-ocular: 0,5/0,6; distância ocelos-margem posterior: $0,2 / 0,3$; distância interocular: 1,6/2; comprimento do tilo: 0,5/0,6; largura do tilo: 0,8/1; comprimento do posclípeo: $1,8 / 2,1 ;$ largura do posclípeo: $0,9 / 1,1 ;$ comprimento do pronoto: $2,3 / 2,6$; largura do pronoto: $3,8 / 4,5$; comprimento do escutelo: $2 / 2,2$; largura do escutelo: $1,7 / 2$; comprimento da tégmina: $8,9 / 9,8$; largura da tégmina: $2,6 / 3,2 ;$ comprimento total: $11,3 / 12,8$.

Caracteres diagnósticos. Coloração geral negra com máculas vermelhas nas tégminas. Tórax e abdômen negros com as margens dos segmentos avermelhadas. Pernas negras com as regiões articulares vermelhas (Figs. 65-67 e 71-73). 

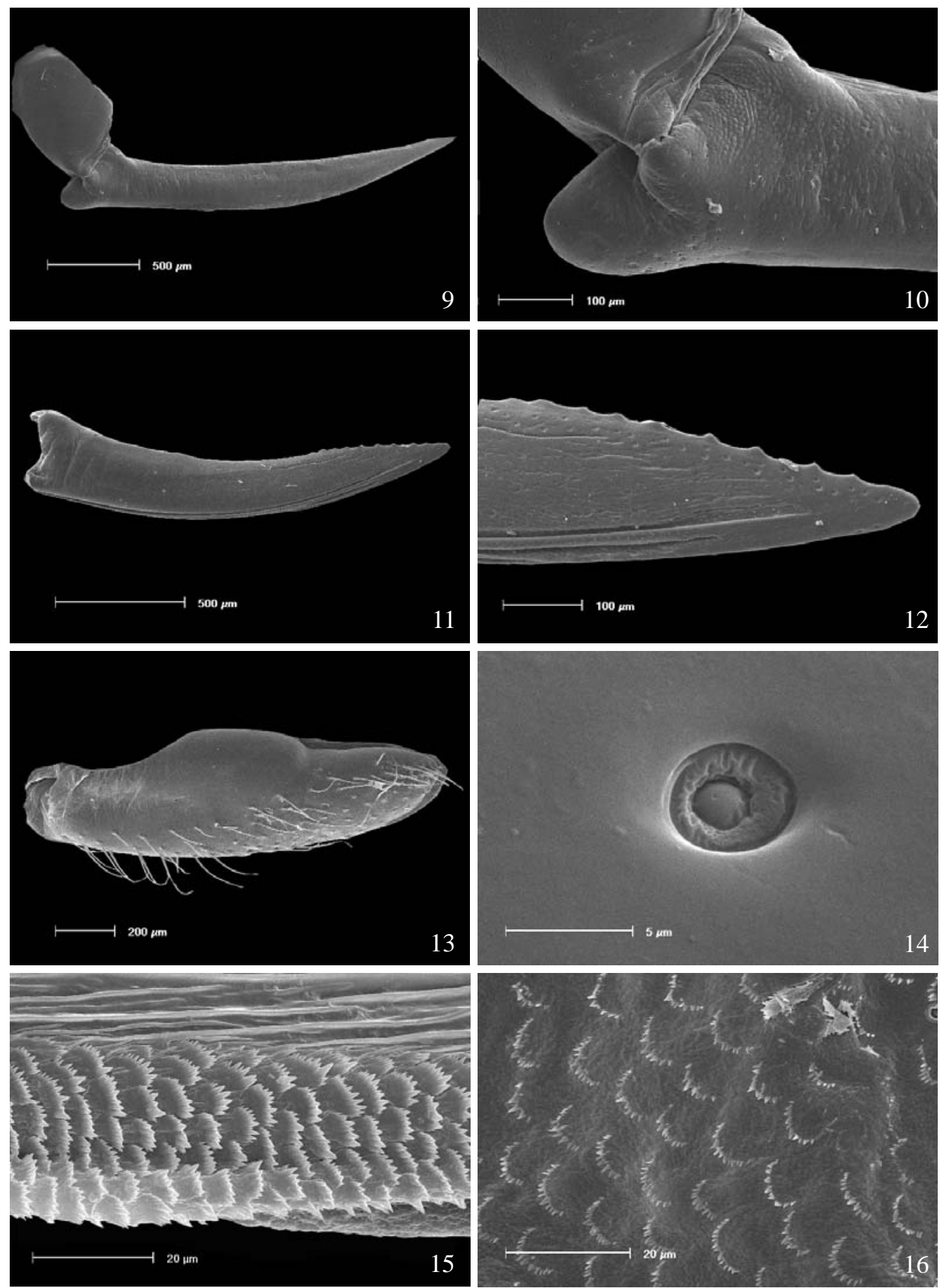

Figs. 9-16. Kanaima katzensteinii, +. Ovipositor: 9, primeira valva, vista lateral externa; 10, processo basal, vista lateral; segunda valva: 11, vista lateral externa; 12, ápice; 13, terceira valva; 14, sensila da segunda valva; ornamentações internas: 15, segunda valva; 16, terceira valva.

Redescrição. Macho. Cabeça negra, mais larga que o comprimento do vértice, este com a superfície puncturada; carena mediana evidente e duas impressões circulares externamente aos ocelos; tilo quadrangular 1,6 vez mais largo que longo, com carena mediana bem marcada; ocelos castanho-claros, separados entre si por mais de um diâmetro de um deles, mais próximos um do outro do que dos olhos e da margem posterior da cabeça; olhos castanho-escuros, com a região periférica amarelada, proeminentes e dispostos transversalmente; antenas com pedicelo negro, visível dorsalmente, corpo basal do flagelo negro, subcilíndrico, projetado para fora do pedicelo, com uma arista menor do que este; posclípeo negro, inflado, de perfil recuado, com ranhuras laterais grosseiramente marcadas e carena longitudinal distinta, 

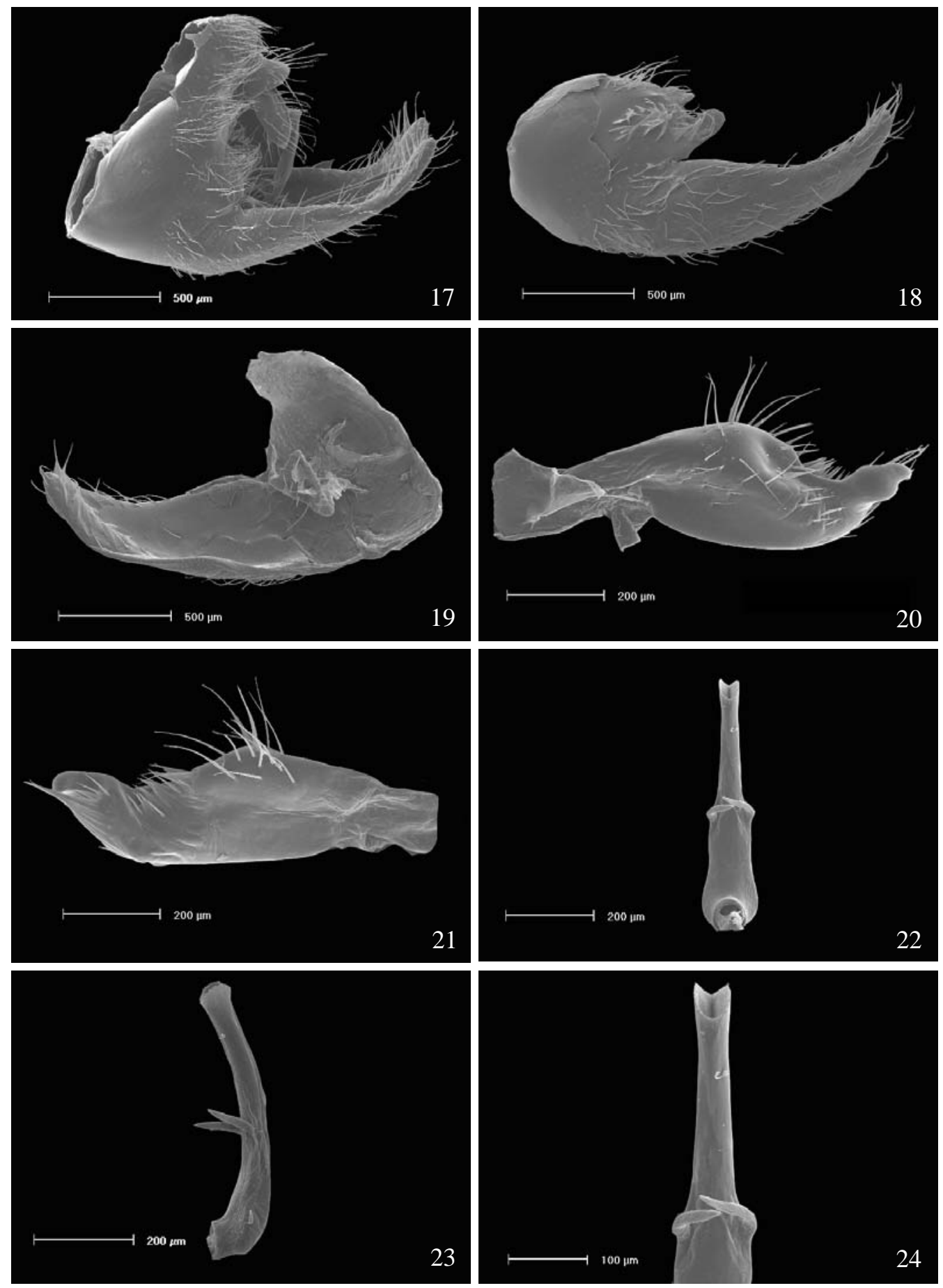

Figs. 17-24. Kanaima fluvialis, ơ. 17, pigóforo, vista lateral; placa subgenital: 18, vista lateral externa; 19, vista lateral interna; parâmero: 20, vista lateral externa; 21 , vista lateral interna; edeago: 22 , vista dorsal; 23 , vista lateral; 24 , ápice.

formando um triângulo no ápice com o tilo; anteclípeo negro maior que o último artículo do rostro, este menor que o anterior; rostro atingindo as mesocoxas, negro com as regiões articulares vermelhas. Pronoto hexagonal, negro, grosseiramente puncturado, margem anterior reta, ânterolaterais ligeiramente convexas, póstero-laterais sinuosas com leve concavidade, posterior chanfrada com reentrância mediana; ângulos umerais arredondados; escutelo negro, com concavidade mediana e rugosidades transversais. Tégminas estreitas, finamente puncturadas, negras com máculas vermelhas; veias $\mathrm{Me} \mathrm{Cu}_{1}$ coalescidas na base, $\mathrm{A}_{1}$ e $\mathrm{A}_{2}$ distintas, venação proeminente; reticulação apical pouco desenvolvida. Asas posteriores hialinas, com venação castanho-escura, $\mathrm{Cu}_{1}$ não espessada na base. Pernas posteriores: fêmur com espinho 
conspícuo na face interna; tíbia com dois espinhos laterais, sendo o basal de igual tamanho que os apicais, estes em número de 15, distribuídos em duas fileiras; basitarso com 23 a 26 espinhos distribuídos em três fileiras e cobertos por uma densa camada de cerdas; processo subungueal ausente.

Genitália do macho. Pigóforo negro, com processo lateral arredondado e pouco desenvolvido entre o tubo anal e a placa subgenital (Fig. 17); esta larga na base com o ápice arredondado (Figs. 18 e 19); parâmeros subretangulares com dente apical voltado para dentro, com intumescimento em sua base, elevação dorsal pouco desenvolvida, margem dorsal e anterior com um conjunto de cerdas (Figs. 20 e 21); edeago subcilíndrico com o ápice alargado e processos dorsais curtos em relação à haste, inseridos na metade do edeago (Figs. 22-24).

Fêmea. Semelhante ao macho, somente maior em tamanho. Primeira valva do ovipositor longa com ápice acuminado, processo basal arredondado e pouco desenvolvido (Figs. 25 e 26); segunda valva longa, margem dorsal com um conjunto de dentes que se estendem além do terço apical, atingindo parte do terço mediano (Figs. 27 e 28), face externa com sensilas dispostas apicalmente nas proximidades da margem dorsal, face interna com ornamentações laminares (Figs. 30 e 31); terceira valva curta e larga com longas cerdas na face ventral e ornamentações na superfície interna (Figs. 29 e 32).

Comentário. K. fluvialis é próxima de $K$. nigra sp. nov. e $K$. fusca comb. nov. compartilhando com estas: intumescimento do espinho do parâmero e dentes da margem dorsal da segunda valva do ovipositor estendendo-se além do início do terço apical. Esta espécie apresenta uma variação no padrão alar, tento sido inclusive, tratada por Lallemand (1924) como possuidora de três variedades: fluvialis com cinco manchas: a primeira no bordo externo próxima à margem costal, a segunda sobre a separação das veias $\mathrm{Me} \mathrm{Cu}_{1}$, a terceira situada sobre o clavo ao nível da primeira, a quarta no bordo externo próxima ao início do terço apical da tégmina, a quinta situada no início do terço apical sobre a veia cúbito; lateralis com somente duas manchas laterais externas no cório; e bipunctata com dois terços anteriores e duas manchas no terço apical vermelhas. Pelo exame do padrão da genitália pode-se afirmar que as subespécies não devem ser aceitas. Cavichioli (1987) realizou um trabalho sobre a biologia da espécie, constatando que as diferenças no padrão alar eram uma variação intraespecífica que ocorria na mesma progênese.

Material examinado. Síntipo - $f$. lateralis P.Alegre/ Brasil// sinal macho// Type// Monecphora fluvialis/ var. lateralis/ Lall/ V. Lallemand det. BRASIL: Paraná: Curitiba, 26.XI.1970, S. Laroca leg., 1 macho, 3 fêmeas (2-DZUP, 3-MCTP); idem: 03.IV.1981, R.R. Cavichioli leg., 4 machos, 1 fêmea (DZUP); idem: 27.III.1981, R.R. Cavichioli leg., 2 machos (DZUP); idem: 08.V.1981, R.R. Cavichioli leg., 1 macho (MCTP); idem: 05.III.1981, R.R. Cavichioli leg., 1 macho (DZUP); idem: 06.XI.1981, A.M. Sakakibara \& R.R. Cavichioli leg., 2 machos, 2 fêmeas (3-DZUP, 2-MCTP); idem: (sem data), A. Paladini leg., 1 fêmea (MCTP); Santa Maria, 25.III.1976, J.M. Amaral leg., 1 fêmea (MCTP); idem: 28.III.1976, G.S. Lorenzoni leg., 1 macho (MCTP); idem: 29.VIII.1976, E.A. Dalcin leg., 1 fêmea (MCTP); idem: 10.X.1976, J.P. Silva leg., 1 fêmea (MCTP); idem: 18.X.1978, J. Luna leg., 1 macho (MCTP); idem: 23.X.1976, J.A. Souza leg., 1 fêmea (MCTP). Rio Grande do Sul: Porto Alegre, 17.X.1979, Ione leg., 1 macho (MCTP) idem: 05.XI.1979, V. Dias leg., sexo ? (MCTP); idem: XI.1979, G.S. Carvalho leg., 1 macho (MCTP); idem: 26.X.1980, G.S. Carvalho leg., 1 fêmea (MCTP); idem: XII.1980, G.S. Carvalho leg., 3 fêmeas (MCTP); idem: 01.XII.1980, L. Jantsch leg., 1 macho (MCTP); idem: 04.XII.1980, G.S. Carvalho leg., 1 fêmea (MCTP); idem: 20.XI.1983, G.S. Carvalho leg., 1 fêmea (MCTP); idem: 28.IV.1984, G.S. Carvalho leg., 3 machos, 4 fêmeas (MCTP); idem: XII.1998, A. Menezes Jr. leg., 1 fêmeas (MCTP); Pelotas, 08.IV.1979, L. Peterman leg., 1 fêmea (MCTP); idem: X.1996, M. Rodrigues leg., 1 fêmea (MCTP); idem: X.1996, F. Jacobson leg., 1 fêmea (MCTP); idem: 17.III.2006, A. Paladini leg., 2 macho, 3 fêmeas (MCTP); idem: 18.III.2006, A. Paladini leg., 3 machos, 2 fêmeas (MCTP); Viamão, 08.X.1994, (sem coletor), 1 fêmea (MCTP); idem: 26.III.1995, Sampaio leg., 1 macho, 1 fêmea (MCTP); idem: 07.VII.1995, A. Petersen leg., 1 fêmea (MCTP); idem: 05.III.1998, P. Prates leg., 4 machos, 3 fêmeas (MCTP); idem: 19.IV.1998, P. Prates leg., 2 fêmeas (MCTP); idem: 09.X.1998, P. Prates leg., 1 macho (MCTP); idem: 22.X.1998, P. Prates leg., 1 fêmea (MCTP); idem: 23.X.2004, G.S. Carvalho leg., 5 machos, 7 fêmeas (MCTP); Capão do Leão, 16.XI.1994, M.K. Cunha leg., 1 macho (MCTP); idem: XI.1996, M. Emmer leg., 1 fêmea (MCTP); Uruguaiana, (sem data), S.D.M. Kracf leg., 1 macho, 1 fêmea (MCTP); Passo Fundo, 12.IV.1968, Luís C. leg., 1 fêmea (MCTP); Triunfo, 16.I.1997, L. Moura leg., 1 macho (MCTP); Guaíba, 01.X.2005, G.S. Carvalho leg., 2 fêmeas (MCTP).

Kanaima fusca (Lallemand, 1927) comb. nov. (Figs. 33-47; 68, 74)

Pachypterinella fusca Lallemand, 1927: 208; Carvalho \& Webb, 2005: 83.

Medidas (em mm). Macho/Fêmea. Comprimento da cabeça: 1,9/1,9; largura da cabeça: 2,9/2,9; diâmetro do ocelo: 0,1/0,1; distância interocelar: 0,3/0,3; distância ocelo-ocular: 0,6/0,6; distância ocelos-margem posterior: $0,2 / 0,2$; distância interocular: 1,9/1,9; comprimento do tilo: $0,5 / 0,5$; largura do tilo: 1,1/1,2; comprimento do posclípeo: 1,7/1,4; largura do posclípeo: $1,1 / 0,8$; comprimento do pronoto: $2,4 / 2,2$; largura do pronoto: 4,2/4,1; comprimento do escutelo: $2,2 / 2,1$; largura do escutelo: $2 / 2,1$; comprimento da tégmina: $10,7 / 10,6$; largura da tégmina: $3 / 3,5$; comprimento total: $13,5 / 13,5$.

Caracteres diagnósticos. Coloração geral castanho-escura, tendendo ao negro na cabeça e no pronoto. Tórax e abdômen castanho-enegrecido com as regiões articulares mais claras. Pernas castanho-claras (Figs. 68 e 74).

Redescrição. Macho. Cabeça negra, mais larga que o comprimento do vértice, este com duas impressões longitudinais externamente aos ocelos, com leve carena mediana e superfície puncturada; ocelos castanho-claros, mais próximos um do outro do que dos olhos, separados entre si por mais de um diâmetro de um deles; olhos castanho-escuros, proeminentes e dispostos transversalmente; tilo negro, quadrangular, mais largo do que longo, com carena mediana distinta; antenas castanho-escuras com pedicelo visível dorsalmente; flagelo com corpo basal subcilíndrico, projetado 

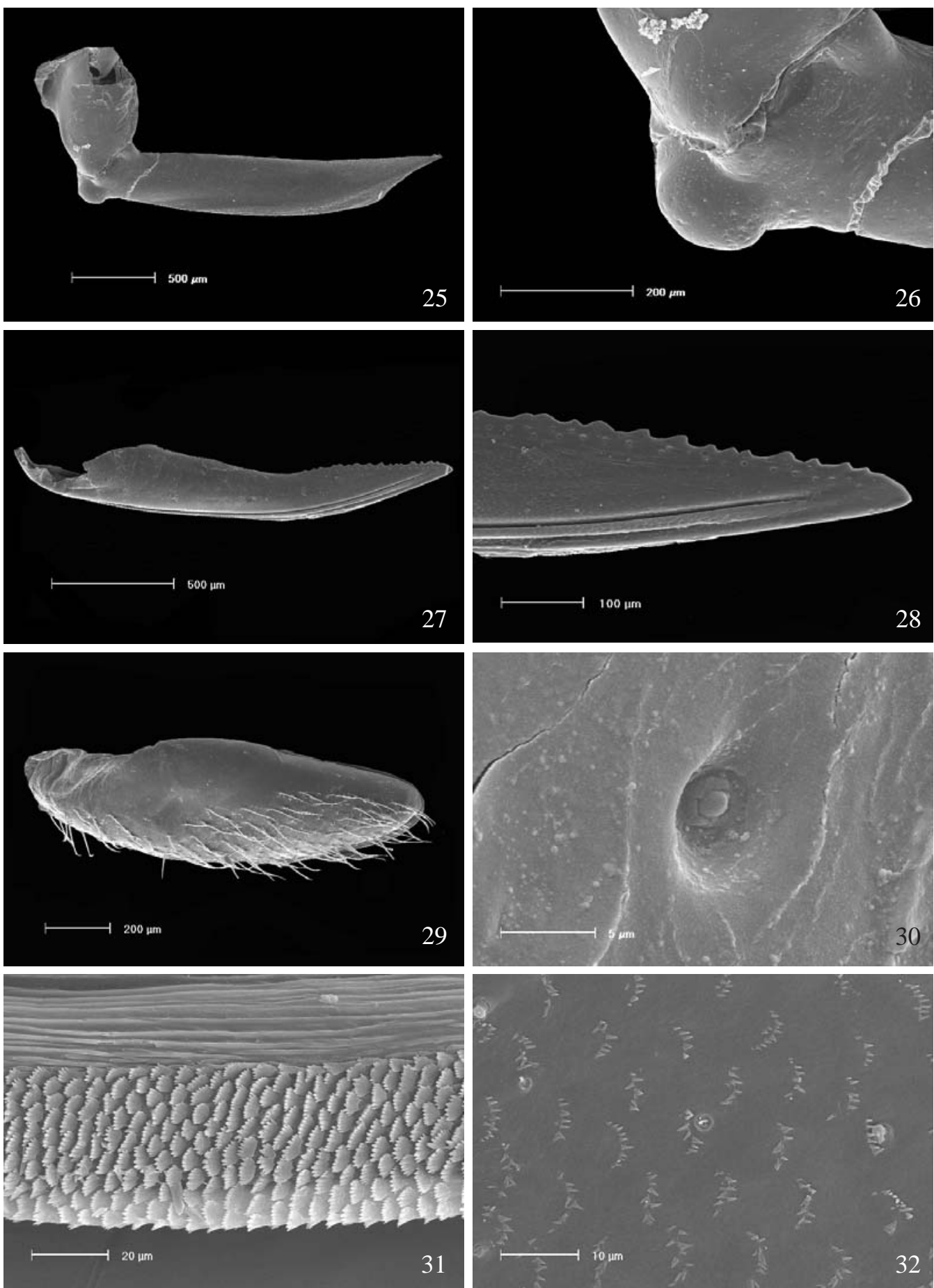

Figs. 25-32. Kanaima fluvialis, + . Ovipositor: 25 , primeira valva, vista lateral externa; 26 , processo basal, vista lateral; segunda valva: 27 , vista lateral externa; 28, ápice; 29, terceira valva; 30, sensila da segunda valva; ornamentações internas: 31, segunda valva; 32, terceira valva.

para fora do pedicelo, com arista menor do que este; posclípeo enegrecido, inflado, de perfil recuado, mais longo do que largo, com carena mediana proeminente formando um triângulo no ápice com o tilo, ranhuras laterais grosseiramente marcadas; anteclípeo castanho-escuro, maior que o último artículo do rostro e este menor que o anterior; rostro castanho, atingindo as mesocoxas. Pronoto negro, hexagonal com carena mediana reduzida e superfície grosseiramente puncturada; margem anterior reta, ântero-laterais retas, póstero-laterais sinuosas com leve concavidade, margem posterior chanfrada com reentrância mediana; ângulos umerais arredondados; escutelo negro com concavidade mediana e rugosidades transversais. Tégmina estreita, castanho-escura, sendo os ápices

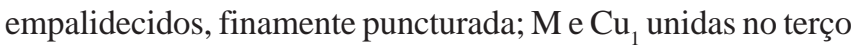



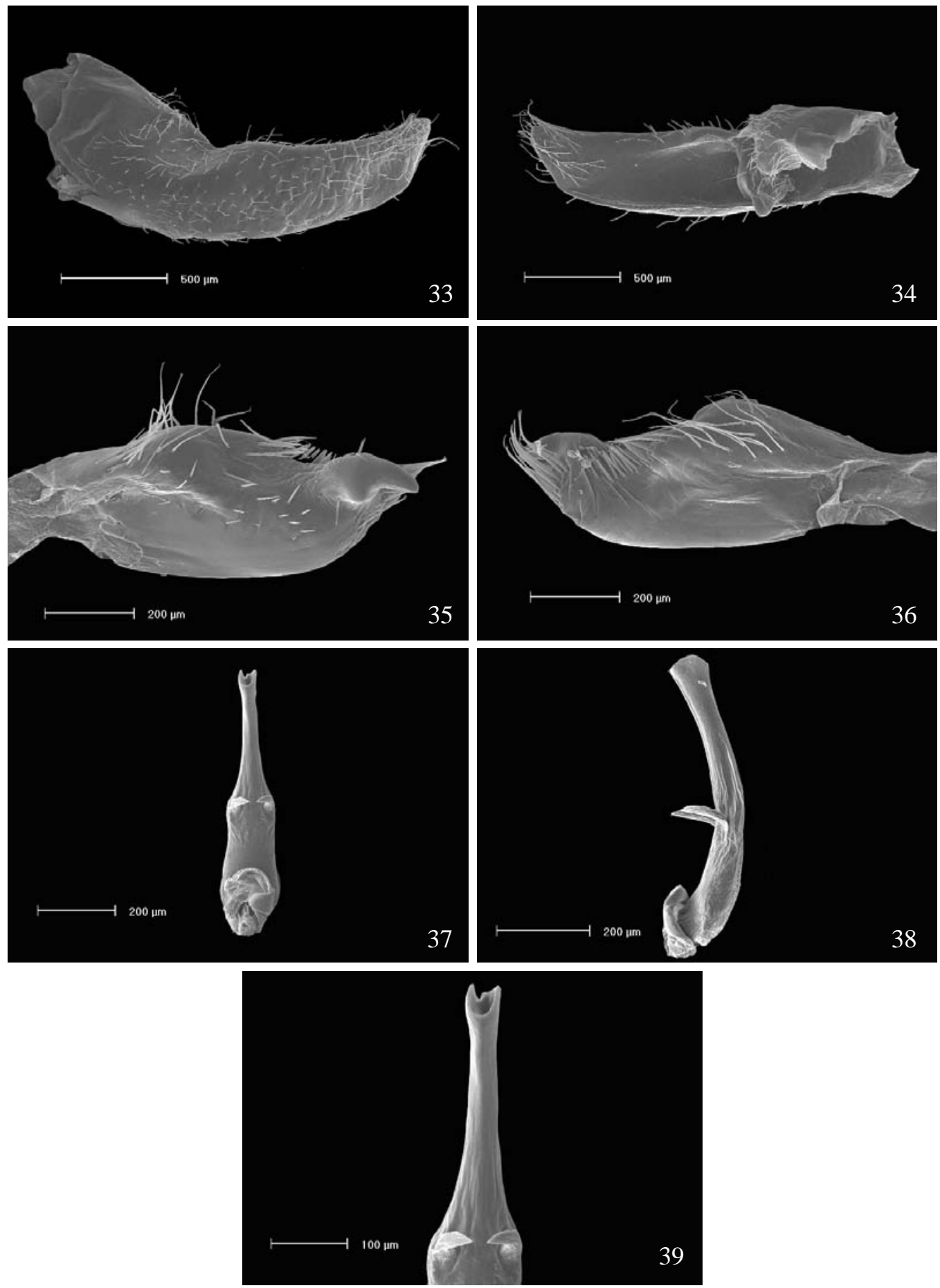

Figs. 33-39. Kanaima fusca comb. nov., ơ. Placa subgenital: 33, vista lateral externa; 34, vista lateral interna; parâmero: 35, vista lateral externa; 36, vista lateral interna; edeago: 37, vista dorsal; 38, vista lateral; 39, ápice.

basal, reticulação apical desenvolvida, veias proeminentes, $\mathrm{A}_{1}$ e $\mathrm{A}_{2}$ distintas. Asas hialinas com venação castanho-escura; $\mathrm{Cu}_{1}$ não espessada na base. Pernas posteriores: fêmur com espinho conspícuo na face interna; tíbia com dois espinhos laterais, sendo o basal de mesmo tamanho que os apicais, estes em número de 15 distribuídos em duas fileiras; basitarso com 26 espinhos apicais distribuídos em três fileiras, cobertos por uma densa camada de cerdas; processo subungueal ausente.

Genitália do macho. Pigóforo castanho-escuro, com um processo lateral entre o tubo anal e a placa subgenital, esta longa em relação ao conjunto, larga na base, com o ápice arredondado (Fig. 33 e 34); parâmeros subretangulares com 

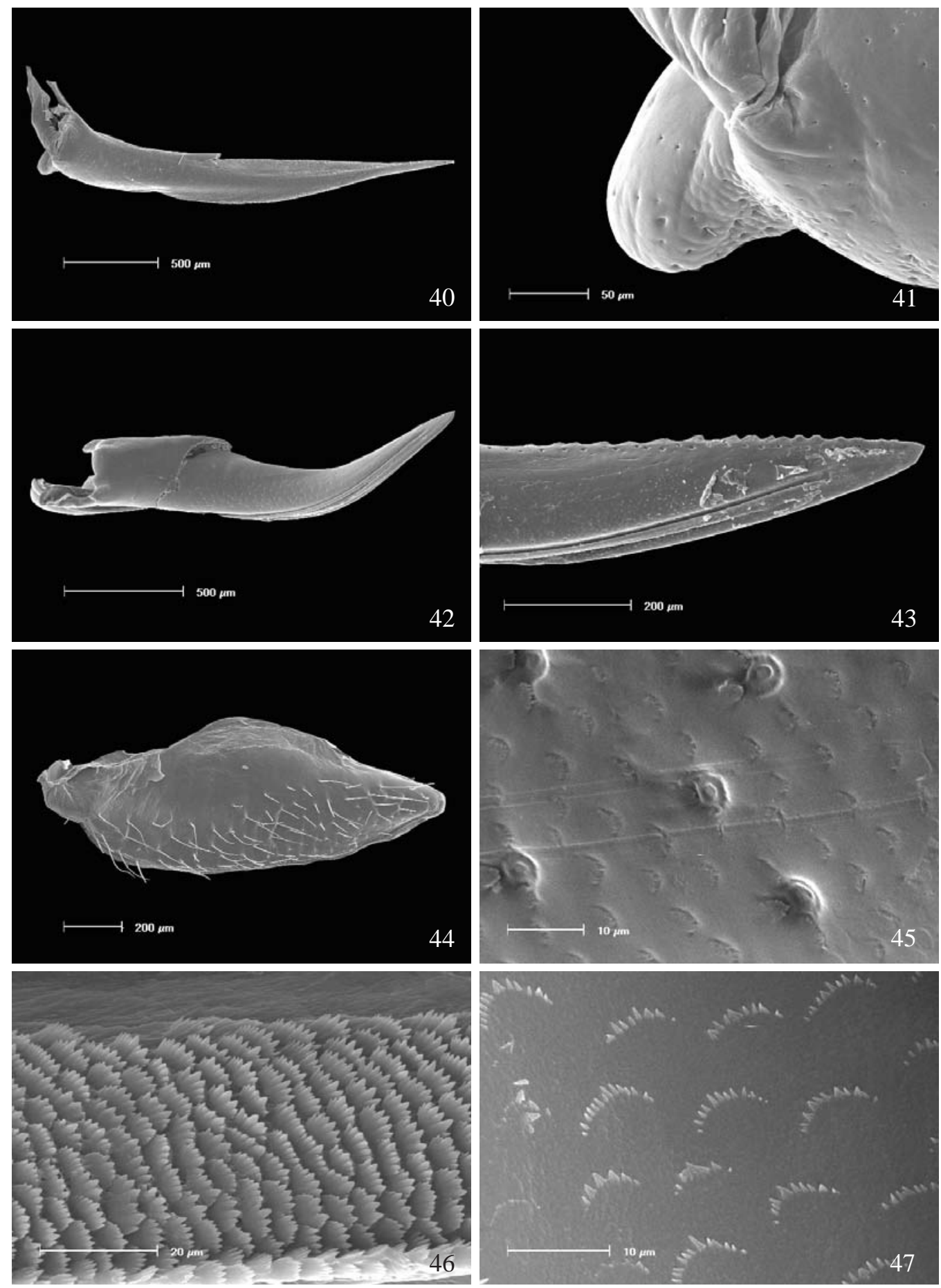

Figs. 40-47. Kanaima fusca comb. nov., ․ Ovipositor: 40, primeira valva, vista lateral externa; 41, processo basal, vista lateral; segunda valva: 42, vista lateral externa; 43, ápice; 44, terceira valva; 45, sensila da segunda valva; ornamentações internas: 46, segunda valva; 47 , terceira valva.

dente apical esclerotizado e voltado para dentro, com intumescimento em sua base; elevação dorsal pouco desenvolvida (Figs. 35 e 36); edeago subcilíndrico, com ápice truncado e alargado, processos dorsais curtos em relação à haste e curvos, inseridos na metade do edeago (Figs.37-39).

Fêmea: Morfologicamente semelhante ao macho, somente um pouco maior. Primeira valva do ovipositor alongada com ápice acuminado, munida de um processo basal arredondado em forma de calcanhar, voltado para baixo e pouco desenvolvido (Figs. 40 e 41); segunda valva do ovipositor longa, com ápice arredondado, terço apical com um conjunto de dentes dorsais, atingindo parte do terço mediano (Figs. 42 e 43), face externa com sensilas localizadas próximas ao ápice, 

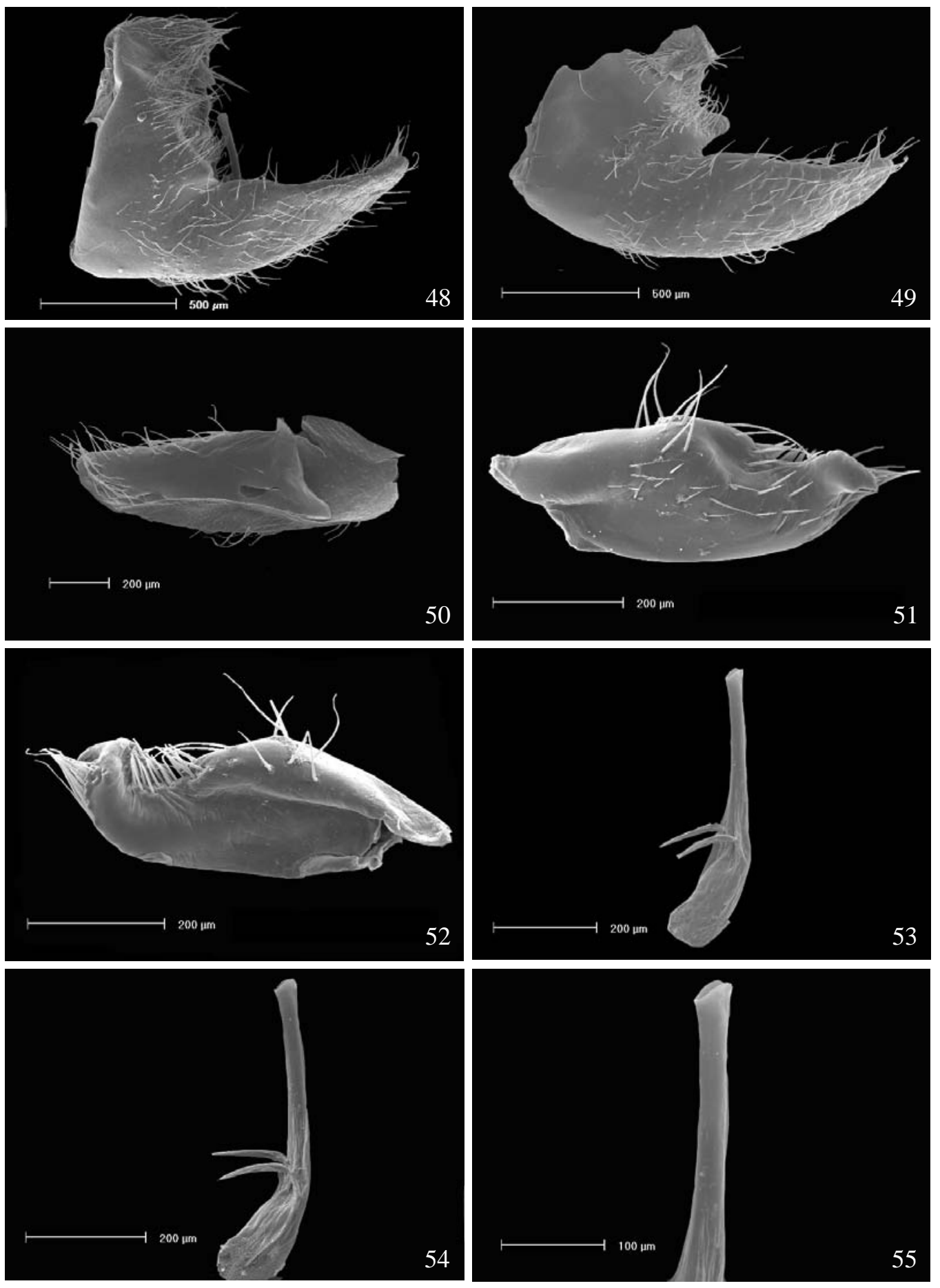

Figs. 48-55. Kanaima nigra sp. nov., $\sigma^{\star}$. 48, pigóforo, vista lateral; placa subgenital: 49, vista lateral externa; 50, vista lateral interna; parâmero: 51, vista lateral externa; 52, vista lateral interna; edeago: 53, vista dorsal; 54, vista lateral; 55, ápice.

face interna com ornamentações laminares (Figs. 45 e 46); terceira valva curta e larga, com longas cerdas na face ventral e ornamentações na face interna (Figs. 44 e 47).

Comentários. Esta espécie pertencia à Pachypterinella, gênero monotípico, também incluído no complexo Mahanarva por Lallemand (1924). Quanto à conformação da genitália do macho, assemelha-se à Kanaima fluvialis, principalmente pela presença de um intumescimento na base do espinho do parâmero. Compartilha três caracteres com as espécies pertencentes à Kanaima: dentículos da face interna da placa subgenital limitando-se à margem dorsal desta; processos dorsais curtos em relação à haste do edeago e ápice do edeago alargado em vista lateral. Não há um caráter exclusivo que 

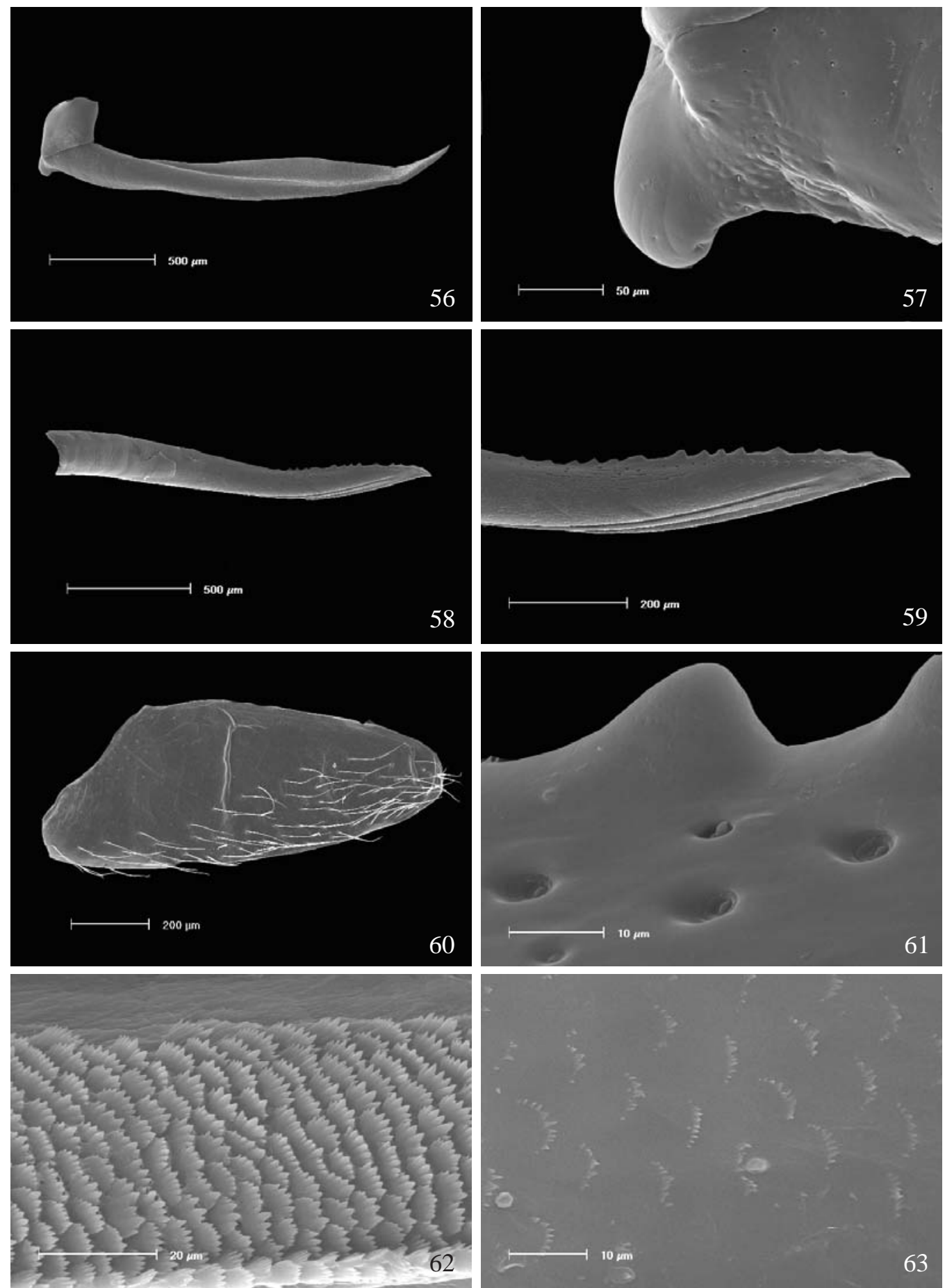

Figs. 56-63. Kanaima nigra sp. nov., ․ Ovipositor: 56, primeira valva, vista lateral externa; 57, processo basal, vista lateral; segunda valva: 58, vista lateral externa; 59, ápice; 60, terceira valva; 61, sensila da segunda valva; ornamentações internas: 62 , segunda valva; 63 , terceira valva.

justifique a manutenção deste gênero e portanto Pachypterinella torna-se sinônimo júnior de Kanaima.

Material examinado. BRASIL: Santa Catarina: Síntipo 우 (BMNH); Rio Grande do Sul: Santa Maria, 30.XI.1976, Z. Castilhos leg. 1 ㅇ (MCTP); Santa Maria, 16. X.1976, J.A. Souza leg. $10^{\pi}$ (MCTP).

\section{Kanaima nigra sp. nov.}

(Figs. 48-63; 69, 75)

Medidas (em mm). Macho/Fêmea. Comprimento da cabeça: 0,8/1; largura da cabeça: 1,9/2,2; diâmetro do ocelo: 0,1/0,1; distância interocelar: 0,2/0,2; distância ocelo-ocular: 0,4/0,5; 

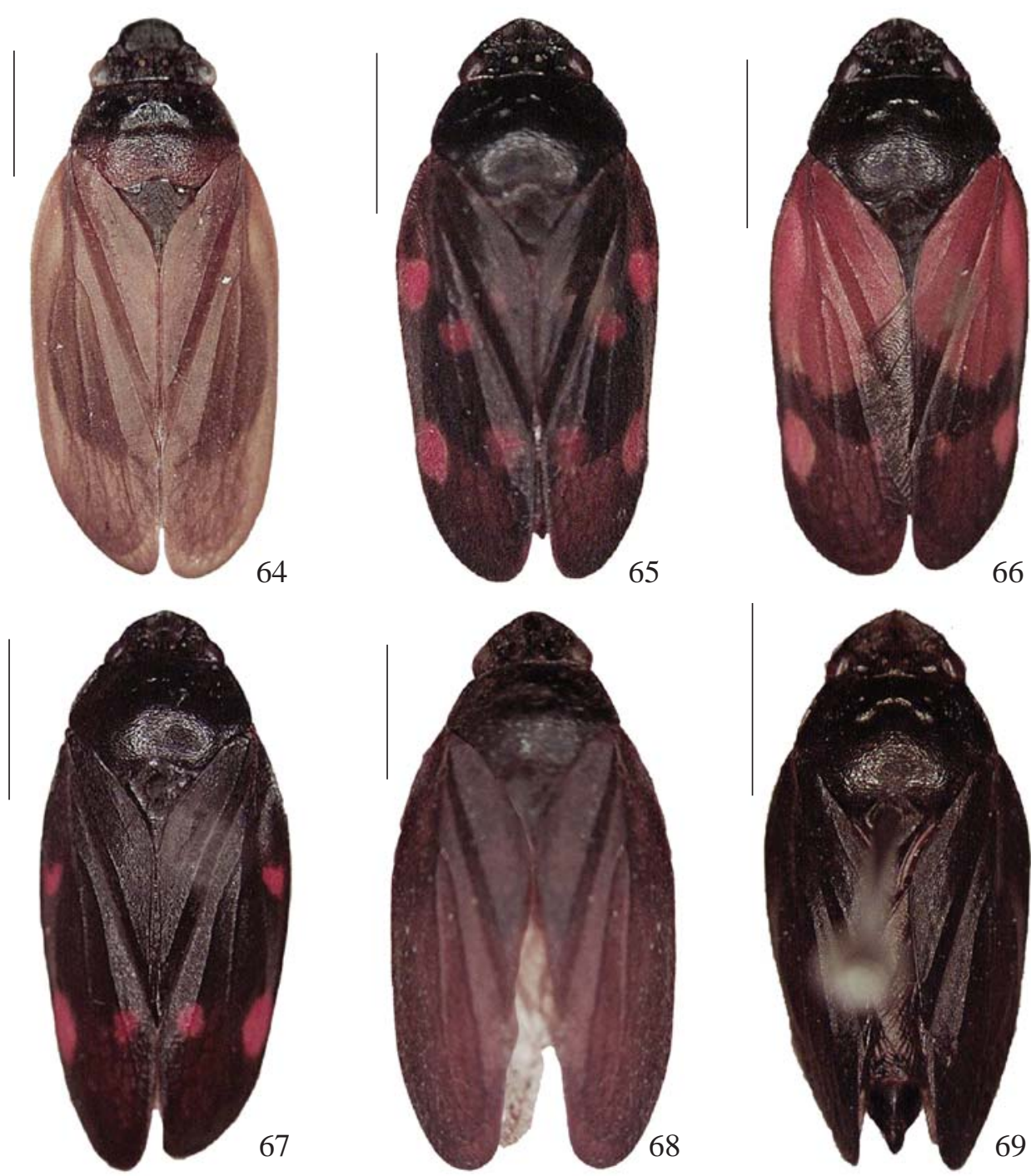

Figs. 64-69. Vista dorsal: 64, K. katzensteinii; 65-67, K. fluvialis; 68, K. fusca comb. nov.; 69, K. nigra sp. nov. (Parátipo + ) Escala = 3 mm.

distância ocelos-margem posterior: $0,2 / 0,2$; distância interocular: $1,3 / 1,4$; comprimento do tilo: $0,3 / 0,4$; largura do tilo: 0,6/0,7; comprimento do posclípeo: 1,3/1,4; largura do posclípeo: 0,7/0,8; comprimento do pronoto: $1,8 / 1,9 ;$ largura do pronoto: $2,8 / 3,2$; comprimento do escutelo: $1,5 / 1,6$; largura do escutelo: 1,2/1,5; comprimento da tégmina: 7/7,6; largura da tégmina: 1,9/2,1; comprimento total: 8,8/9,5.

Caracteres diagnósticos. Coloração geral negra; tégminas negras podendo ter duas máculas vermelho-claras: uma situada na margem costal, entre o terço anterior e médio, acima da veia $\mathrm{R}$; outra sobre a veia $\mathrm{R}_{2+3}$ no terço apical. Tórax, abdômen e pernas negras, com regiões articulares marrom-avermelhadas (Figs. 69 e 75).

Descrição. Holótipo macho. Cabeça negra, mais larga que o comprimento do vértice, este com carena mediana levemente marcada; margem supra antenal negra; tilo quadrangular, 1,7 vez mais largo que longo, com carena mediana proeminente; ocelos castanhos, separados entre si por mais de um diâmetro de um deles, mais próximos um do outro do que dos olhos e da margem posterior da cabeça; olhos castanho-escuros com região periférica mais clara, proeminentes e dispostos transversalmente; antenas com o pedicelo negro, não visível dorsalmente, corpo basal do flagelo negro, subcilíndrico, projetado para fora do pedicelo e portando uma arista menor do que este; posclípeo negro, inflado, de perfil recuado, mais longo que largo, com ranhuras laterais grosseiramente marcadas, carena longitudinal distinta e proeminente, formando um triângulo no ápice com o tilo; anteclípeo negro, maior que o último artículo do rostro e este menor que o anterior; rostro negro, atingindo as mesocoxas. Pronoto negro, sendo as regiões próximas ás margens póstero-laterais de coloração mais clara, grosseiramente puncturado com leve pubescência marrom; margem anterior reta, ântero-laterais retas, póstero-laterais sinuosas, posterior chanfrada com uma reentrância mediana, ângulos umerais arredondados; escutelo negro com concavidade mediana e rugosidades transversais. 


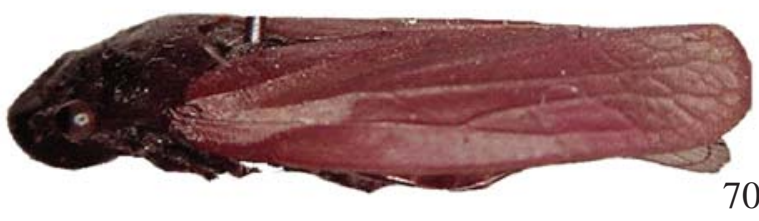

70
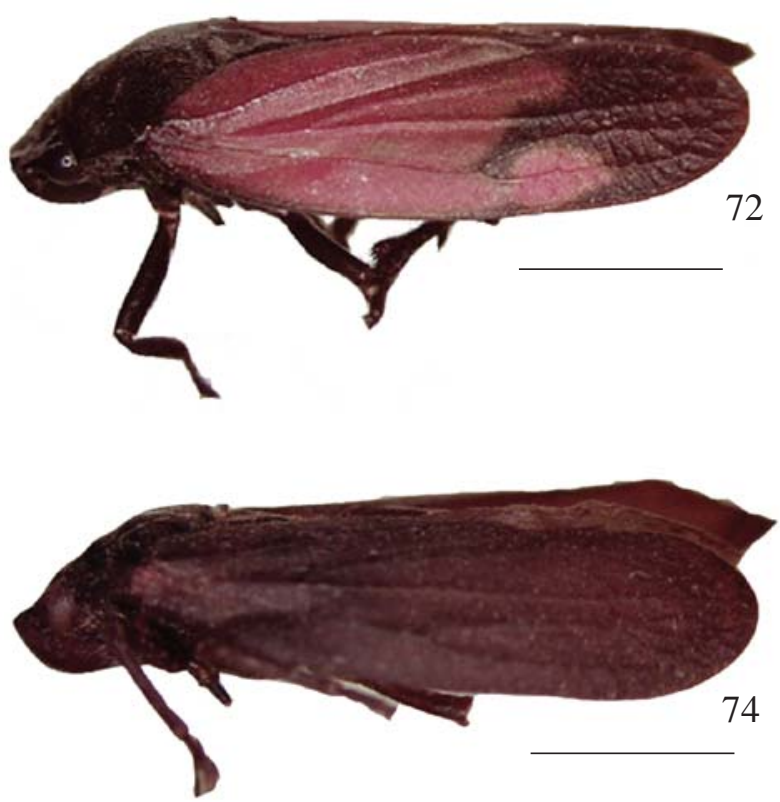
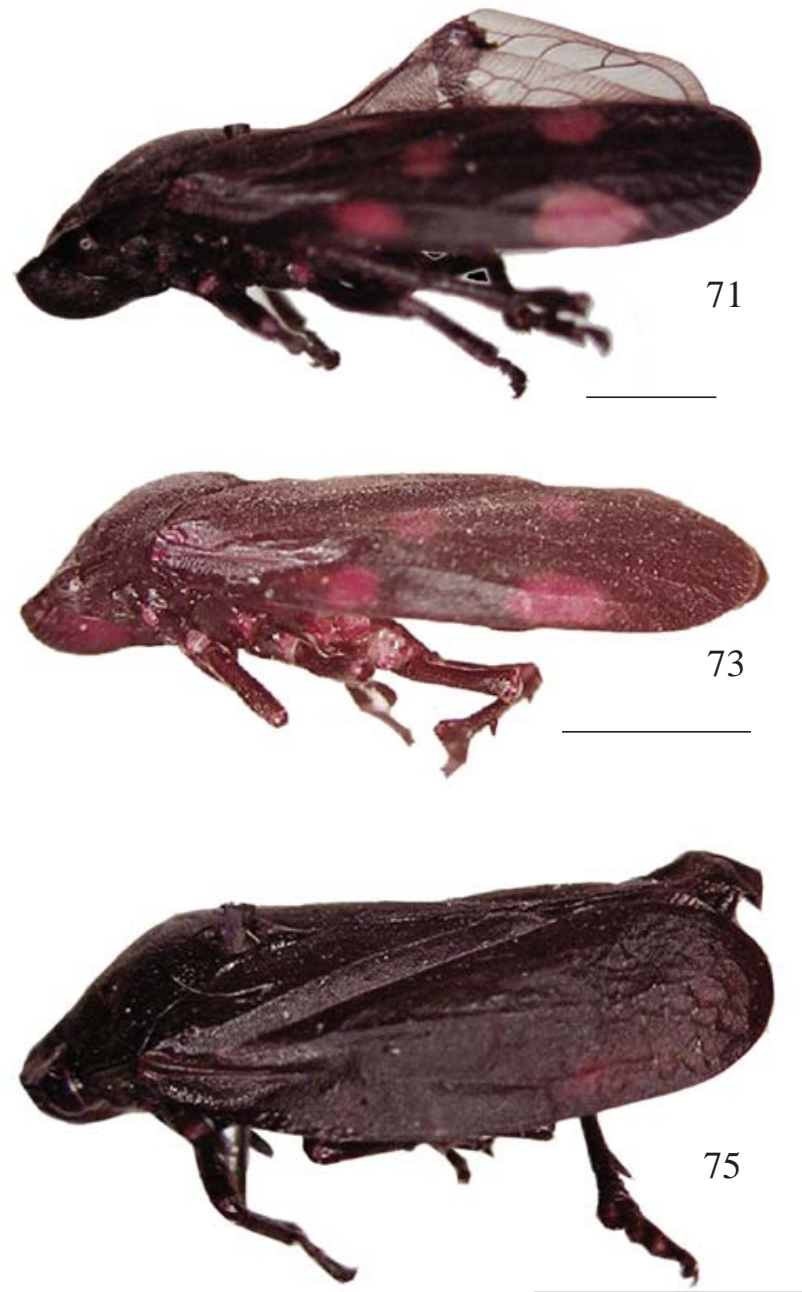

Figs. 70-75: Vista lateral: 70, K. katzensteinii; 71-73, K. fluvialis; 74, K. fusca comb. nov.; 75, K. nigra sp. nov. (Parátipo o +) Escala $=3$ mm.

Tégminas estreitas, de coloração negra, finamente puncturadas, com veias proeminentes; $\mathrm{M}$ e $\mathrm{Cu}_{1}$ unidas no terço basal; $\mathrm{A}_{1}$ e $\mathrm{A}_{2}$ distintas, reticulação apical pouco desenvolvida. Asas hialinas com venação enegrecida, $\mathrm{Cu}_{1}$ não espessada na base. Pernas posteriores: fêmur com espinho conspícuo na face interna, tíbia com dois espinhos laterais, sendo o basal de igual tamanho aos apicais, estes em número de 14 distribuídos em duas fileiras; basitarso com 19 espinhos apicais distribuídos em três fileiras e cobertos por uma densa camada de cerdas; processo subungueal ausente.

Genitália do macho. Pigóforo negro, com um processo digitiforme entre o tubo anal e a placa subgenital (Fig. 48), esta alargada e longa em relação ao conjunto, com ápice arredondado (Figs. 49 e 50); parâmeros subretangulares com elevação dorsal pouco desenvolvida e ápice arredondado, dente apical voltado para dentro, com intumescimento na base, margem dorsal e anterior com cerdas curtas (Figs. 51 e 52); edeago subcilíndrico com a base alargada e ápice truncado; processos dorsais curtos em relação à haste, curvos e com os ápices voltados para baixo, inseridos abaixo da metade do edeago (Figs. 53-55).
Fêmea. Morfologicamente semelhante ao macho, somente um pouco maior. Primeira valva do ovipositor longa com ápice acuminado, processo basal pouco desenvolvido, arredondado, voltado para baixo (Figs. 56 e 57). Segunda valva do ovipositor longa com ápice arredondado, terço apical com um conjunto de dentes dorsais, atingindo parte do terço mediano (Figs. 58 e 59), face externa munida de sensilas, face interna com ornamentações laminares (Figs. 61 e 62); terceira valva curta e larga, munida de cerdas na face ventral com esculturações na face interna (Figs. 60 e 63).

Comentários: $K$. nigra é encontrada sobre uma espécie de gravatá rasteiro, Eryngium elegans Cham. \& Schlecht. (Apiaceae). Apesar do tamanho pequeno, conclui-se que esta espécie deve ser enquadrada em Kanaima devido ao hábito e as características morfológicas tais como: dentículos da face interna da placa subgenital limitando-se à margem dorsal desta; processos medianos curtos em relação à haste do edeago e ápice do edeago alargado em vista lateral. Alguns espécimes, principalmente os machos podem apresentar uma ou duas máculas vermelhas nas tégminas: uma situada na margem 
costal, entre o terço basal e médio, acima da veia R; e a outra ao nível de $\mathrm{R}_{2}+\mathrm{R}_{3}$, próxima a porção apical da asa.

Esta espécie é a mesma citada erroneamente na figura 32, como K. nova no artigo da análise de Kanaima (Paladini, Ferrari \& Carvalho 2008). K. nigra compartilha com $K$. fusca e $K$. fluvialis os seguintes caracteres: intumescimento do espinho do parâmero e dentes da segunda valva do ovipositor estendendo-se além do terço apical.

Etimologia: O epíteto específico é alusivo à coloração negra, que é predominante no inseto.

Material examinado. Holótipo $\sigma^{\star}$, BRASIL, Rio Grande do Sul: Taquari, 04.V.2001, G.S. Carvalho, leg. (MCTP). Parátipos: Rio Grande

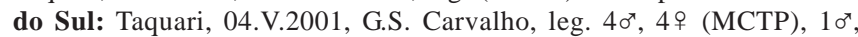
1 우 (DZUP); Pelotas, 17.III.2006, A. Paladini, leg. 2 우 (MCTP).

Mahanarva (Ipiranga) vittata (Walker, 1851) comb. nov.

Monecphora vittata Walker, 1851: 681

Tomaspis vittata (Walker, 1851) Metcalf, 1961: 115

Mahanarva (Ipiranga) fortunata (Lallemand, 1924) comb. nov.

Monecphora fortunata Lallemand, 1924: 383

Kanaima vittata Fennah, 1979: 270

Mahanarva (Mahanarva) radiata (Walker, 1851) comb. nov.

Monecphora radiata Walker, 1851: 677

Tomaspis radiata (Walker, 1851) Metcalf, 1961: 109

Kanaima radiata (Walker, 1851) Fennah, 1968: 181

\section{Mahanarva (Mahanarva) dubia (Stancik \& Cavichioli, 2003) comb. nov.}

Kanaima dubia Stancik \& Cavichioli, 2003

Kanaima vittata (Walker, 1851) Fennah, 1979: 270

Agradecimentos. Ao CNPq pela concessão da bolsa de mestrado. Ao Dr. Rodney Ramiro Cavichioli (DZUP) pelo empréstimo de material. Ao Dr. Cláudio Augusto Mondin (PUCRS) pela identificação do material botânico. À equipe do Laboratório de Malacologia da PUCRS pela utilização do equipamento fotográfico. À Miriam Souza dos Santos, do Centro de Microscopia e Microanálises (CEMM) da PUCRS, pelo apoio e paciência na manipulação do MEV.

\section{REFERÊNCIAS}

Berg, C. 1879. Hemiptera Argentina (Continucion) Soc. Cient. Argentina. Anales de la Sociedad Científica Argentina 8: 209-226.

Berg, C. 1883 addenda et Emendanda ad Hemiptera Argentina. Anales de la Sociedad Científica Argentina 8: 209-226.

Carvalho, G.; Webb, M. D. 2004. A new genus and nine new species of Neotropical Spittlebugs (Hemiptera, Cercopidae, Tomaspidini). Revista Brasileira de Entomologia 48: 383-389.
Cavichioli, R. R. 1987. Sobre a Biologia de Kanaima fluvialis (Lallemand, 1924) (Homoptera, Cercopidae). Revista Brasileira de Entomologia 31: 71-82.

Cavichioli, R. R. 1988. Estudo sobre a Morfologia de Kanaima fluvialis (Lallemand, 1924) (Homoptera, Cercopidae). Revista Brasileira de Entomologia 32: 394-410.

Deletang, L. F. 1917. Notas hemipterológicas. Apuntes sobre los generos argentinos de Cercopidos. Physis 2: 263-271.

Distant, W. L. 1909. Rhyncotal Notes - XLVI Annals and Magazine of Natural History 3: 187-213.

Fennah, R. G. 1949. New Genera and Species of Neotropical Cercopidae (Homoptera). Annals and Magazine of Natural History 1: 605-620.

Fennah, R. G. 1951. Further notes on Neotropical Cercopoidea. Annals and Magazine of Natural History 4: 136-149.

Fennah, R. G. 1953. Revisionary Notes on Neotropical Monecphorine Cercopoidea (Homoptera). Annals and Magazine of Natural History 6: 337-360.

Fennah, R. G. 1968. Revisionary Notes on the New World Genera of Cercopid Froghoppers (Homoptera: Cercopoidea) Bulletin of Entomological Research 69: 165-190.

Fennah, R. G. 1979. Revisionary Notes on the New World Genera of Cercopid Froghoppers (Homoptera: Cercopoidea) Bulletin of Entomological Research 69: 267-273.

Hamilton, K. G. A. 1981. Morphology and Evolution of the Rhynchotan Head (Insecta: Hemiptera, Homoptera) The Canadian Entomologist 113: 953-974.

Lallemand, V. 1912. Homoptera. Fam. Cercopidae. Genera Insectorum 143: 1-167. pls 8f.

Lallemand, V. 1924. Homoptères nouveaux de La Collection du Museum National de Paris et de la mienne. Bulletin du Museum d' Histoire Naturelle Paris 1924: 201-207.

Lallemand, V. 1927a. Desciption d'une nouvelle espece de Cercopidae constituant un nouveau genre. Annales de La Societe Entomologique de France 96: 208.

Lallemand, V. 1927b. Descriptions de cercopides nouveaux provenant de la collection du British Museum. Transactions of the Royal Entomological Society of London 75: 99-118.

Lallemand, V. 1931. Qualques especes et varietes nouvelles de Cercopides Exotiques des collections du Musee Zoologique de Hamburg. Folia Zoologica e Hydrobiologica 2: 164-169.

Lallemand, V. 1938. Notes sur les Cercopidae. Bulletin et Annales de la Société Entomologique de Belgique 78: 137-147.

Metcalf, Z. P. 1960. A Bibliography of the Cercopoidea. General Catalogue of the Homoptera. Raleigh, NC. North Carolina State College. Fasc. VI, 266 p.

Metcalf, Z. P. 1961. General Catalogue of the Homoptera. Raleigh, NC. North Carolina State College. Fasc. VI, part. 2, Cercopidae, $616 \mathrm{p}$.

Nielson, M. W. 1965. A revision of the genus Cuerna (Homoptera, Cicadellidae) Technical Bulletin. United States Department of Agriculture 1318: 1-48.

Paladini, A.; A. Ferrari \& G. S. Carvalho. 2008. Cladistic Analysis of Kanaima Distant, 1909 (Hemiptera, Cercopidae). Zootaxa 1704: 47-63.

Papavero, N. 1994. Fundamentos práticos de taxonomia zoológica: coleções, bibliografia, nomenclatura. 2.ed. rev. e ampl. São Paulo, Editora da Universidade Estadual Paulista, 285 p.

Snodgrass, R. E. 1935. Principles of insect morphology. New York, NY : McGraw-Hill, 667 p. : il.

Stancik, J. F. \& R. R. Cavichioli. 2003. Kanaima Distant, 1909: Descrição de uma nova espécie (Hemiptera, Auchenorrhyncha, Cercopidae, Tomaspidinae). Revista Brasileira de Entomologia 47: $9-14$

Walker, F. 1851. List of the specimens of Homopterous insects in the collection of the British Museum 3: 637-907. 